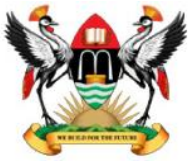

East African School of Higher Education Studies \& Developmen
Makerere Journal of Higher Education

ISSN: 1816-6822; 7 (2) (2015) 105 - 116

DOI: http://dx.doi.org/10.4314/majohe.v7i2.7

(C) The Author(s) 2015

Reprints \& permission: EASHESD

http://ajol.info/majohe

\title{
Effect of Instructional Medium on Students' Performance: A Comparison of Reading and Oral Instruction in Nigeria
}

\author{
Katrina A. Korb ${ }^{1,}{ }^{*}$, Binfa Kelvin Gono ${ }^{1}$, Samuel Adekunle Jinadu ${ }^{1}$, Abangom Ruth \\ John ${ }^{1}$, Gabriel N. Mwoltu ${ }^{1}$, Rimdan Nanle Oona ${ }^{1}$ \\ ${ }^{1}$ University of Jos [* Corresponding author: katrina.korb@gmail.com]
}

\begin{abstract}
Nigeria has a rich oral tradition. In the pre-literate Nigerian culture, knowledge and wisdom were shared through the oral methods of proverbs and storytelling. However, in modern formal education, knowledge is communicated largely through text. The purpose of this paper was to compare students' performance based on these instructional mediums. Two studies using a betweensubjects experimental design were conducted among Nigerian university students. Both studies included two conditions: lecture (oral) and reading (text). In both conditions, the same content was presented. In the reading condition, students read the content as an article whereas in the lecture condition, students listened to the content as a lecture. Post-test examination performance was then compared. Both experiments found that reading resulted in considerably higher academic performance than lecturing.
\end{abstract}

Keywords: Instructional medium; Curriculum innovation; Teaching and learning

\section{$1 \quad$ Introduction}

In the modern world, most knowledge is communicated through text. Students, particularly in tertiary institutions, are required to learn primarily by reading textbooks and reviewing notes from class (McKeachie \& Svinicki, 2006). In many tertiary classrooms, lectures are designed to clarify and supplement what students read in their textbooks, meaning that reading is the primary teaching method. However, learning primarily from a text requires a high level of reading comprehension because students do not just read the text, but also must learn new information from what was read.

In contrast to modern tertiary education, Nigeria's educational practices are historically rooted a rich oral tradition (Abubakar, 2011). In the pre-literate culture, knowledge and wisdom were passed down through the oral methods of 
proverbs and storytelling (Kiarie, 2010; Omolewa, 2007). Oral tradition was used to teach history, culture, religion, philosophy, and character values. For example, the proverb, "If you refuse to be made straight when you are green, you will not be made straight when you are dry" is commonly used to emphasize the importance of early education. Folk stories, such as those about how things came into being, provided lessons in character and critical thinking (see Why Mosquitoes Buzz in Peoples' Ears, Aardema, 1975). Therefore, much of learning in Nigeria traditionally occurred through oral teaching methods.

Furthermore, Nigeria has frequently been criticized for having a poor reading culture (Griswold, McDonnell, \& McDonnell, 2006). Most Nigerians rarely read, except to pass examinations in school (Fayose, 2004). Furthermore, literacy rates are low in Nigeria. In 2010, the global average adult literacy rate was $84 \%$, whereas Nigeria's adult literacy rate was $61 \%$ (UNESCO Institute for Statistics, 2012a, 2012b). Nigeria even ranks below average in adult literacy rates compared to other countries within sub-Saharan Africa, which have an average adult literacy rate of $63 \%$. Even amongst individuals who have completed schooling, reading comprehension is very low (Oyetunde, 2002). In other words, students may be able to read a text, but not gain much new knowledge from what they read. Indeed, students who do little independent reading outside of school typically have difficulties profiting from technical texts designed to teach content knowledge in school (Snow, 2002). Accordingly, it could be expected that Nigerian students may not learn well through reading.

The combination of traditional oral teaching methods, poor reading culture, and a low level of reading comprehension amongst Nigerian students may mean that Nigerian students learn more effectively through oral instructional methods, not reading as is expected by tertiary institutions. Therefore, the purpose of this study was to compare Nigerian students' academic performance when comparing reading (text) and lecture (oral) instructional methods. Academic performance was conceptualized in terms of two variables: recognition and retention. Recognition was measured by forced-choice items where students only had to recognize the answer. Retention was measured by open-ended items where students had to retain what was taught, and then recall it from memory. Furthermore, two affective variables of interest in the topic and valuing of the topic were also included as dependent variables.

\subsection{Research Hypotheses}

1. There is no significant difference between lecture and reading instructional medium on students' recognition (forced-choice items).

2. There is no significant difference between lecture and reading instructional medium on students' retention (open-ended items). 
3. There is no significant difference between lecture and reading instructional medium on students' interest in the topic.

4. There is no significant difference between lecture and reading instructional medium on students' valuing of the topic.

This article reports the results of two different studies that test these same four hypotheses, but under different experimental conditions. The first study used a more controlled research design where the only difference between the two groups was whether the course content was communicated via lecture or reading. Based on the findings of the first study, a second study was conducted that had stronger ecological validity. The second study allowed students in the lecture condition to take notes as is typically done in lectures. In the second study, the lecture and reading conditions were controlled by the amount of time that students were allowed to study. The Methodology, Findings, and Discussion of these two studies are reported separately.

\section{$2 \quad$ Study 1}

\subsection{Methodology}

\subsubsection{Research Design}

The research design was a between-subjects experimental design with two conditions: lecture (oral) and reading (text). The exact same course content was given in two instructional mediums. In the reading (text) condition, students read the content in an article. In the lecture (oral) condition, students heard the content in a lecture, which was communicated orally to students verbatim from the text that was read in the previous condition. Since the content was identical in the two conditions, a comparison of student performance at the end of the study determined whether Nigerian students learn better by reading a text, listening to an oral lecture, or there was no difference in academic performance between the two.

The content of the course was positive psychology, which was used because it was a topic that was not covered in any of the participants' typical courses. This means that performance on the post-test would only be a result of what they had learned in the course of the experiment. Participants were randomly assigned into the two conditions using the hat and draw method. The four dependent variables included recognition, retention, interest, and valuing of the content. 


\subsubsection{Participants}

The participants for this research were 140 psychology students enrolled in the 200-level experimental research methods course at the University of Jos, Nigeria. The University of Jos is a federal university in the middle belt of Nigeria, which draws students from all geo-political zones across Nigeria. The convenience sampling technique was used. A majority of the students were male (male $=84$, female $=49,7$ missing) with an average age of 24.41 years.

\subsubsection{Instrument}

Academic performance was operationalized as the variables of recognition and retention. The first variable, recognition, was measured by ten forced-choice items measuring participants' understanding of the course content. Each item had four options apiece. The correct answer for each item attracted one point.

The second variable, retention, was measured by three open-ended examination questions based on the lecture. The marking scheme for these questions resulted in ten total points. Total scores were summed for both academic performance variables.

The affective variables, interest and valuing, were measured by seven items apiece from the Intrinsic Motivation Inventory (Ryan, 1982). For both sets of items, participants indicated how they felt about the subject matter (positive psychology) on a Likert Scale from 1 (not at all true) to 7 (very true). The seven interest items that measured participants' interest were designed to measure interest or enjoyment in a particular activity which, in this context, was positive psychology.

The valuing items assessed how relevant or useful a particular activity is to oneself which, again, in this context was positive psychology. Validity evidence for the Intrinsic Motivation Inventory has been gathered by McAuley, Duncan, and Tammen (1987).

\subsubsection{Data Collection Procedure}

A three-page article about positive psychology was developed that overviewed the history of positive psychology, operationally defined happiness, and outlined five strategies for improving happiness based on empirical research. This was used as the subject of the text that participants in the reading condition read and participants in the lecture condition heard orally.

The study took place in one class session. First, the hat-and-draw method was used to randomly assign all students to either the lecture or reading conditions. This resulted in a total of 70 students in each condition. The students assigned to the reading condition stayed in the classroom whereas the students assigned to the lecture condition were moved to a different, but similar classroom. 
Once the participants in the two conditions were settled into different classrooms, a research assistant described the study procedures following a standardized script. Students were told a cover story that the purpose of the experiment was to determine how classroom atmosphere influences students' academic performance. Students were also falsely informed that their performance on the exam would affect their course grades to ensure that students were focused and paying attention throughout the course of the study.

Reading condition. In the reading condition, students were given ample time, about twenty minutes, to read the article on positive psychology independently. Research assistants monitored the room to ensure that the students were focused on the reading and did not take notes. Once students finished reading the article, they were asked to raise their hands. Then the research assistants collected the articles. This was done to ensure that the students in the reading condition did not use extra time to re-read the material as this would have biased the outcome of the study because these students would have been exposed to the content multiple times.

Lecture condition. In the lecture condition, a lecturer read the exact same article to the students. While the lecturer did not deviate from the text, he used voice inflection and eye contact to ensure that the students' attention was engaged. The lecture lasted for about twenty minutes.

Administration of Post-Test. Immediately after both conditions were finished, the instrument to measure the dependent variables was administered to students in both conditions. Research assistants monitored the classrooms to ensure students completed the instrument independently. The post-test took about twenty minutes.

After the examination, the two conditions were re-joined and a debriefing was done by the researcher. Students were informed of the real purpose of the study and assured that there would be no course credit given for their performance on the examination. The entire experiment took about forty-five minutes.

To protect the participants in the study, students voluntarily participated in the study. Anonymity was ensured by not allowing students to write their name on the instrument. Though a benign cover story was given for the purpose of the study, a complete debriefing was conducted with all participants.

\subsubsection{Data Analysis}

Independent samples t-test was used to compare performance between the two conditions. The t-test is used whenever two groups are compared on a continuous variable. The text and oral groups were statistically independent groups, which is why the independent samples t-test was selected. 


\section{$2.2 \quad$ Findings}

A $t$-test was used to compare the lecture and reading conditions for all dependent variables. Cohen's $d$ was used to calculate the effect sizes for significant results by dividing the difference between the means by the pooled standard deviation (Cohen, 1988). Large, medium, and small effect sizes for Cohen's $d$ are greater than .80, .50, and .20 respectively (Cohen, 1992). The results are shown in Table 1.

Table 1: $t$-test Comparing Lecture and Reading Conditions on Dependent Variables

\begin{tabular}{lllllllll}
\hline & \multicolumn{2}{c}{ Lecture } & \multicolumn{2}{c}{ Reading } & & & \\
& Mean & SD & Mean & SD & $t$ & df & p & d \\
\hline Recognition & 4.67 & 1.66 & 6.14 & 1.94 & 4.81 & 137 & $<.001^{*}$ & 0.81 \\
Retention & 3.36 & 2.91 & 6.61 & 2.52 & 7.05 & 137 & $<.001^{*}$ & 1.19 \\
Interest & 5.29 & 1.41 & 6.04 & 1.02 & 3.57 & 137 & $<.001^{*}$ & 0.61 \\
Value & 6.25 & 0.83 & 6.45 & 0.79 & 1.41 & 136 & .161 & \\
\hline
\end{tabular}

${ }^{*} p<.05$.

The first hypothesis stated that there is no significant difference between lecture and reading instructional medium on students' recognition (forced-choice items). As can be seen in Table 1, the first null hypothesis was rejected, suggest that there is a statistically significant difference in recognition between students in the lecture condition and those in the reading condition, with the reading condition performing significantly better than the lecture condition. The effect size between the two conditions is large. The grading scale commonly used in Nigeria includes the following ranges: A (70-100\%), B (60-69\%), C (50-59\%), $\mathrm{D}(45-50 \%), \mathrm{E}(40-44 \%)$, and $\mathrm{F}$ ( $39 \%$ and below). The average test score on the recognition test for participants in the lecture condition reflect a " $D$ " whereas the average test score for the participants in the reading condition was a " $\mathrm{B}$ ".

The second null hypothesis stated that there is no significant difference between lecture and reading instructional medium on students' retention (openended items). From Table 1, this null hypothesis was also rejected, with a very large effect size. There is a statistically significant difference between lecture and reading as instructional medium on retention, with students in the reading condition demonstrating better retention compared to students in the lecture condition. The difference between the two conditions was larger than recognition. Students in the reading condition had an average retention score of a " $\mathrm{B}$ " on the Nigerian grading scale whereas students in the lecture condition had an average retention score of an "F".

The third hypothesis stated that there is no significant difference between lecture and reading instructional medium on students' interest in the topic. Results from Table 1 show that the null hypothesis was rejected. Therefore, the 
difference in students' interest between the lecture condition and reading condition was statistically significant with a medium effect size. Students in the reading condition demonstrated greater interest in the topic compared to students in the lecture condition.

The final null hypothesis stated that there is no significant difference between lecture and reading instructional medium on students' valuing of the topic. The null hypothesis was accepted, so there was no significant difference between lecture and reading instructional medium on students' valuing of the topic.

\subsection{Discussion}

Results from the first experiment showed that reading as an instructional medium led to significantly better academic performance than lecture. In both recognition and recall examination questions, students who read the article had an average performance of a $\mathrm{B}$, whereas students who received the information as lecture had an average performance of a D and F, respectively. Furthermore, students in the reading condition also showed greater interest in the topic of positive psychology than students in the lecture condition.

The outcome of this study was quite compelling. However, the experimental procedures led to a rather artificial learning situation. Students in the lecture condition were not allowed to take notes. Some research has shown that simply taking notes can improve learning (Kobayashi, 2005). Therefore, students may learn more from lecture when they are allowed to take notes, which is standard practice in tertiary classrooms.

To further test the effect of instructional medium on student performance, a second experiment was conducted to reflect a more realistic learning environment in order to improve the ecological validity of the findings. In the second experiment, time was controlled between the two conditions in that participants in both conditions were given 40 minutes to study, either through reading or lecture. The second experiment was conducted in the next academic year with students who were freshly admitted into the department and thus would not have been exposed to the study procedures.

\section{$3 \quad$ Study 2}

\subsection{Methodology}

\subsubsection{Research Design}

The same between-subjects experimental research design with two conditions of lecture and reading was used as Experiment 1. 


\subsubsection{Participants}

The participants for Experiment 2 were 66 new psychology students enrolled in the 100-level history of psychology course at the University of Jos. The demographic characteristics were similar to Experiment 1 though students were approximately one year younger. A majority of the students were male (male $=41$, female $=20,5$ missing) and an average age of 23.71 years. There were 31 students in the lecture condition and 35 students in the reading condition.

\subsubsection{Instrument}

The same instrument was used as Experiment 1 to measure the four dependent variables of recognition, retention, interest, and valuing.

\subsubsection{Procedure for Data Collection}

The procedures were similar to Experiment 1 with only slight modifications. Both conditions were given 40 minutes exactly to study. Students in the lecture condition were allowed to take notes during the lecture. After the lecture concluded, students were allowed to use the remaining time to review their notes (about 15 minutes). Students in the reading condition were also allowed to take notes on the article, and allowed to review the material as often as they liked within the allotted timeframe. At the end of 40 minutes, all students cleared their desks and the post-test was administered.

\subsubsection{Data Analysis}

The same method of data analysis was followed as in Experiment 1.

\subsection{Findings}

The results for Study 2 are presented in Table 2. Hypothesis 1 stated that there is no significant difference between lecture and reading instructional medium on students' recognition. The results were significant with a large effect size. This result provides further support that reading as an instructional medium enhances student recognition more than lecture. On the typical Nigerian grading scale, students in the reading condition scored an average of a B, whereas students in the lecture condition scored an average of a D.

Hypothesis 2 stated that there is no significant difference between lecture and reading instructional medium on students' retention. The results were significant with a medium effect size, also indicating that reading rather than lecture aids students' retention. Students in the reading condition scored an 
average of an "A" whereas students in the lecture condition scored an average of a "B".

Table 2: $t$-test Comparing Lecture and Reading Conditions on Dependent Variables

\begin{tabular}{lcccccccc}
\hline & \multicolumn{2}{c}{ Lecture } & \multicolumn{2}{c}{ Reading } & & & & \\
& Mean & SD & Mean & SD & $t$ & df & p & d \\
\hline Recognition & 4.68 & 1.70 & 6.63 & 2.39 & 3.78 & 64 & $<.001^{*}$ & 0.93 \\
Retention & 6.00 & 2.74 & 7.26 & 2.02 & 2.14 & 64 & $0.036^{*}$ & 0.53 \\
Interest & 5.90 & 0.96 & 6.12 & 0.99 & 0.91 & 63 & 0.366 & \\
Value & 6.50 & 0.66 & 6.46 & 0.99 & -0.22 & 63 & 0.827 & \\
\hline
\end{tabular}

${ }^{*} p<.05$.

Hypothesis 3 stated that there is no significant difference between lecture and reading instructional medium on students' interest in the topic. This result was not significant. Therefore, the null hypothesis was retained. Hypothesis 4 stated that there is no significant difference between lecture and reading instructional medium on students' valuing of the topic. This result is also not significant. Thus, the null hypothesis is retained. There was no significant effect of instructional medium on either of the affective dependent variables.

\subsection{Discussion}

The purpose of Experiment 2 was to replicate Experiment 1 in a more realistic learning environment in order to improve the ecological validity of the findings, allowing students in the lecture condition to take notes and review their notes. To this end, time was the controlled factor between the two conditions of lecture and reading. The results of Study 2 largely replicate the findings of Study 1. In both studies, students who read the subject matter of positive psychology performed significantly better than students who listened to the material. Overall, the difference in academic performance between the lecture and reading conditions were smaller in the second experiment, when students in the lecture condition were allowed to take notes and study their notes. However, students in the reading condition still considerably out-performed students in the lecture condition even in the more realistic setting.

Though the research findings are mixed (see Bligh, 1998) there is evidence that in the West, students learn better when reading than through lecture (Hartman, 1961). Thus, the finding of this study that Nigerian students performed better when reading material than when listening to lecture is consistent with findings amongst other students around the world. However, this finding contradicted the original premise that motivated this study: that the combination of traditional oral teaching methods, poor reading culture, and a 
low level of reading comprehension amongst Nigerian students may mean that Nigerian students learn more effectively through oral instructional methods. This study clearly refuted this premise: Nigerian students do not learn more effectively through oral instructional methods.

However, Study 2 did not replicate the significant difference between the lecture and reading conditions on the affective dependent variable of interest in the topic. In Experiment 1, students in the reading condition had higher interest in the topic of positive psychology than the students in the lecture condition. This finding is in line with Blight's (1998) conclusion that lecture is ineffective for inspiriting interest in a topic. Whereas the formal instrument measuring interest showed no significant difference between the lecture and reading conditions in Experiment 2, casual observation of the engagement of students provided evidence that most students in the reading condition were actively engaged in the topic for most of the 40 minute period, whereas many students in the lecture period appeared disengaged from the topic, particularly toward the end of the 40 minute period. Further research should be conducted to determine whether instructional medium impacts students' engagement in learning.

Therefore, the findings of this study reveal that reading as an instructional medium is superior to lecture amongst Nigerian students. However, this does not negate the importance of lectures for Nigerian students. Indeed, there are a number of advantages of lecture as an instructional medium in tertiary education when compared to reading. Lectures allow students to ask questions when they do not understand the material, and lectures also provides a local context for information, neither of which can be done when reading is used as the exclusive instructional medium.

Thus, the combination of lecture and assigned reading for each lecture that is common in most Western tertiary institutions is likely the most effective model for maximizing learning. However, due to the paucity of reading materials available to both students and lecturers in Nigeria, many Nigerian classes draw primarily, and sometimes exclusively, on lecture as an instructional medium. The findings of this study provide evidence that lecture as the only instructional medium will likely have a negative impact on student learning, and perhaps even interest in the topic.

\section{Conclusion and Recommendation}

The purpose of this study was to compare Nigerian students' academic performance when comparing reading (text) and lecture (oral) instructional methods. Both experiments found that reading resulted in considerably higher academic performance than lecturing, with large effect sizes. There was also 
tentative evidence that reading results in greater interest in the topic. Therefore, lecturers must ensure that reading assignments are incorporated in the course development to ensure that learning is maximized in tertiary education.

Since reading as an instructional medium was found to result in higher academic performance, lecturers should ensure that each lecture is supplemented by reading assignments to help students develop in-depth understanding of the topic. Due to the paucity of reading materials in Nigeria, lecturers must write high-quality textbooks that can supplement their lectures. Furthermore, the Government must make efforts to reduce the cost of importing textbooks.

Additional research should be conducted to expand the findings of this study. The population for the study consisted of university students, who are only the top minority of students throughout Nigeria. Perhaps the results would be different amongst a different population of students, including secondary school students or students at other types of tertiary students such as polytechnics. Because secondary school students are more representative of students throughout Nigeria, the original premise of this study may hold true.

\section{Acknowledgements}

The authors would like to appreciate other members of the research team who helped collect the data, including Joseph Queen Ladi, Keziah Daam, Maren David Amos, and Paul Joshua Oyakose.

\section{References}

Aardema, V. (1975). Why mosquitoes buzz in people's ears: A West African Tale. New York: Puffin Books.

Abubakar, A. A. (2011). Proverbs as sources of philosophical ideas about African education. In A. B. Nsamenang \& T. M. S. Tchombe (Eds.), Handbook of African educational theories and practices: A generative teacher education curriculum (pp. 67-76). Bamenda, Cameroon: Human Development Resource Centre.

Bligh, D. A. (1998). What's the use of lectures? Exeter, UK: Intellect.

Cohen, J. (1988). Statistical power analysis for the behavioural sciences $\left(2^{\text {nd }}\right.$ Ed.). Hillsdale, NJ: Lawrence Erlbaum Associates.

Cohen, J. (1992). A power primer. Psychological Bulletin, 112, 155-159.

Fayose, P. O. (2004). Not only books for Africa but a reading culture too. Keynote address presented at the $29^{\text {th }}$ International Board on Books for Young people (IBBY) Congress. Cape Town, South Africa. 
Griswold, W., McDonnell, E. M., \& McDonnell, T. E. (2006). Glamour and honour: Going online and reading in West African culture. Information Technologies and International Development, 3, 37-52.

Hartman, F. K. (1961). Recognition learning under multiple channel presentation and testing conditions. Audio Visual Communication Review, 9, 24-43.

Kiarie, D. (2010). Reclaiming Africa's traditions in the arts and culture of words. Retrieved on August 16, 2010 from $\mathrm{http} / / /$ artsociety.suite $101 . \mathrm{com} /$ article.cfm/reclaiming-africas-traditionalculture-of-words

Kobayashi, K. (2005). What limits the encoding effect of note-taking? A metaanalytic examination. Contemporary Educational Psychology, 30, 242-262.

McAuley, E., Duncan, T., \& Tammen, V. V. (1989). Psychometric properties of the Intrinsic Motivation Inventory in a competitive sport setting: A confirmatory factor analysis. Research Quarterly for Exercise and Sport, 60(1), 48-58.

McKeachie, W. J., \& Svinicki, M. (2006). McKeachie's teaching tips: Strategies, research, and theory for college and university teachers. Boston: Houghton Mifflin Company.

Omolewa, M. (2007). Traditional African modes of education: Their relevance in the modern world. International Review of Education, 53, 593-612.

Oyetunde, T. O. (2002). Second language reading: Insights from Nigerian primary schools. The Reading Teacher, 55, 748-755.

Ryan, R. M. (1982). Control and information in the intrapersonal sphere: An extension of cognitive evaluation theory. Journal of Personality and Social Psychology, 43(3), 450-461.

Snow, (2002). Reading for understanding: Toward an $R \& D$ program in reading comprehension. Santa Monica, CA: RAND.

UNESCO Institute for Statistics. (2012a). Adult and youth literacy. Retrieved from: http://www.uis.unesco.org/literacy/Documents/fs20-literacy-day-2012en-v3.pdf.

UNESCO Institute for Statistics (2012b). National literacy rates for youths (1524) and adults (15+). Retrieved from: http://unstats.un.org/unsd/demographic/products/socind/Dec.\%202012/4a.xls 